\title{
BMJ Open To close or not to close? Analysis of 4 year's data from national surveillance of norovirus outbreaks in hospitals in England
}

\author{
John P Harris, ${ }^{1,2}$ Goutam K Adak, ${ }^{1,2}$ Sarah J O’Brien²
}

To cite: Harris JP, Adak GK, O'Brien SJ. To close or not to close? Analysis of 4 year's data from national surveillance of norovirus outbreaks in hospitals in England. BMJ Open 2014:4:e003919. doi:10.1136/bmjopen-2013003919

- Prepublication history and additional material for this paper is available online. To view these files please visit the journal online (http://dx.doi.org/10.1136/ bmjopen-2013-003919).

Received 29 August 2013 Revised 2 December 2013 Accepted 6 December 2013

CrossMark

\begin{abstract}
${ }^{1}$ Gastrointestinal Emerging and Zoonotic Diseases Department, Public Health England, London, UK ${ }^{2}$ University of Liverpool Institute of Infection and Global Health and National Consortium for Zoonosis Research, Neston, UK
\end{abstract}

Correspondence to John P Harris: john.harris@phe.gov.uk

\section{ABSTRACT}

Objective: To assess the impact of ward or bay closures, specifically, whether prompt closure of an affected ward shortens the duration of norovirus outbreaks and the resulting disruption in hospitals.

Design: Analysis of summary data from hospitals on outbreaks of norovirus from 2009 to 2012.

Methods: Using a large outbreak surveillance dataset, we examined the duration of outbreaks, duration of disruption, ward closures, the number of patients and staff affected and the number of lost bed-days, as functions of the timing of closure. We conducted Quasi-Poisson regression analyses to assess the effect of ward closure (timing of closure) on outcome measures, controlling for time of year (winter or summer), ward size and ward type (elderly care wards).

Results: Regression analysis indicates that after controlling for season ward size and type, the duration of outbreak and duration of disruption were shorter, fewer patients were affected by the time of closure and fewer patients were affected overall, when closure occurred promptly (within 3 days of the first case becoming ill) compared with non-prompt closure groups. However, in outbreaks where wards were not closed, the length of outbreaks were similar to the prompt closure group and also had fewer patients and staff affected and fewer cases per day of outbreak compared with prompt closure.

Conclusions: Closing a bay or ward promptly in an outbreak of norovirus leads to a shorter duration of outbreaks, a shorter duration of disruption and fewer patients being affected compared with outbreaks where wards were not promptly closed. However, the interpretation of these results is not straightforward. The outbreaks where the ward was not closed at all have similar characteristics in terms of the duration of outbreak and fewer people were affected compared with the baseline prompt closure group.

\section{INTRODUCTION}

Outbreaks of diarrhoea and vomiting due to norovirus are common in hospitals. These outbreaks can be disruptive, affect many

\section{Strengths and limitations of this study}

- A large standardised data set for analysis.

- This analysis provides a baseline should infection control strategies move away from wholeward closures as the new guidelines suggest.

- A weakness is that analysis was carried out on summary data collected on outbreaks from a national web-based reporting scheme, which makes it difficult to unpick some of the questions around the ward characteristics which influence differences in the outcomes.

patients and staff, lead to ward closures and cancelled operations due to staff sickness and lost bed-days. Norovirus outbreaks can occur at any time of year but most of the outbreaks happen during winter months, a time when there are increased competing demands for hospitals services. ${ }^{1}{ }^{2}$ Estimates for the cost of norovirus outbreaks vary between US $\$ 650000$ for a single outbreak in the USA, ${ }^{3} £ 115$ million nationally for England $^{4}$ and $£ 1.2$ million over a 2-year period in one region in Scotland. ${ }^{5}$

Evaluating the effectiveness of individual components of infection control measures is challenging, and the published literature on infection control measures do not provide definitive answers. ${ }^{6}$ Measures introduced to control outbreaks, such as cohort or barrier nursing, enhanced cleaning, visitor restrictions and ward closures, are implemented concurrently, rather than individually. One observational study suggested that closing bays or wards within 3 days of the first person becoming ill shortened the length of norovirus outbreaks. ${ }^{4}$

Recent cost effectiveness and simulation studies $^{78}$ question the need for a complete ward closure. In addition, new multiagency guidelines in the UK on the control of norovirus outbreaks in hospitals and care homes 
move away from a strategy of whole-ward closure to one of the managing strategies within bays. ${ }^{9}$ Guidelines in the USA recognising the paucity of strong evidence suggest that the decision of ward closure should be based on risk assessment by infection prevention personnel. The categorisation of this measure in the US guidelines is described as a weak recommendation and that the evidence for ward closure is low quality. ${ }^{10}$

Using a large outbreak surveillance dataset, we aimed to assess the impact of ward or bay closures, specifically whether prompt closure of an affected ward shortens the duration of norovirus outbreaks and the resulting disruption in hospitals.

\section{METHODS}

\section{Data sources}

We used data from the national Hospital Norovirus Outbreak Reporting Scheme (HNORS), established by the Health Protection Agency (HPA) in 2009. This reporting scheme collects summary data on the outbreaks of diarrhoea and vomiting that occur in hospitals in England that are either laboratory confirmed or are suspected to be due to norovirus. Users of the system are provided with definitions in order to standardise the surveillance.

\section{Outbreak definition}

Outbreaks were defined as follows: Suspected outbreak: two or more patients who have either two episodes of vomiting or diarrhoea, or one episode of diarrhoea and vomiting, occurring on a ward within the hospital without laboratory confirmation. A confirmed outbreak: as above with laboratory confirmation of norovirus (where at least one specimen is positive for norovirus).

Most of the National Health Service (NHS) laboratories use either PCR or ELISA for detection of norovirus. For the purposes of reporting to HNORS, the HPA does not set minimum standards on what constitute laboratory confirmation; this is determined locally and it is accepted that an outbreak is laboratory confirmed if reported as such. Outbreaks on each ward are treated as distinct events. Outbreaks are considered over, if 7 days have elapsed following the last onset date of the last affected patient.

The reporting scheme is web-based and infection control teams based in the hospitals enter the data directly via a secure Internet database. Data items collected include first and last date of onset of illness, whether wards or bays were closed, dates of ward or bay closure, laboratory confirmation of norovirus, ward type, the number of patients or staff involved in the outbreak and the number of lost bed-days. The number of lost bed-days is the cumulative number of beds unavailable for use for each day of closure. The closure is defined as the restriction of new patient admissions, transfers into or discharges from the affected unit (ward or bay within the ward). Where a reporter chooses YES when answering the question on ward closure, they are then prompted to provide the date of closure and reopening. There is no option for $\mathrm{NO}$ and therefore leaving this blank assumes that no closure occurred.

\section{Data analysis}

The duration of outbreak was determined as the number of days between the date of onset of illness of the last patient and the date of onset of illness of the first patient plus 1 day (because the date after the last person was ill is the first date on which the outbreak had finished). The duration of closure was the number of days between the date of reopening the ward and the date of closing the ward. The duration of disruption was calculated as the number of days between the date of reopening the ward and the date of onset of illness in the first known case. Where there was no indication that the ward had closed (the question is left blank in the online form) we have assumed this meant there was no closure.

Outbreak reports from community settings (such as psychiatric units) or with no information on ward type were not laboratory confirmed, and single outbreaks that were recorded as involving multiple wards were excluded from the analysis.

\section{Statistical comparisons}

We examined the duration of outbreaks, ward closures and disruption, the number of patients and staff affected and the number of lost bed-days, as functions of the timing of closure. We also estimated the number of people affected on each day of the outbreak, calculated as the total number of people affected during the outbreak (staff plus patients) divided by the length of the outbreak (as defined above). We also used this measure to estimate the number of patients affected by the time the closure occurred. Outbreaks were classified into four groups (1) prompt closure, where closure occurred within 3 days of the first reported date of onset of illness, (2) closed between 4 and 6 days of the first reported onset date, (3) closed seven or more days after the first reported onset date and (4) not closed. Group 1 , prompt closure, was the baseline group in our analysis. The 3-day cut-off for prompt closure was chosen because the only previous study showing any association with shorter outbreak duration used this cut-off and this seemed a reasonable hypothesis to test.

The data on all outcome variables were right skewed and transformation of the data did not normalise the data, so non-parametric tests were conducted to assess the differences between groups (Wilcoxon Rank Sum tests for two group analysis and Kruskal-Wallace tests for more than two groups). In the first instance, comparison between closure groups was conducted. However, factors such as size of the ward, ward type (elderly care ward) and time of year (winter) might be related to the duration of outbreaks and also affect the number of people affected during the outbreak, and confound the 
relationship of the apparent impact of ward closure. Three groups for ward size were created (based on the distribution of the number of beds reported in each ward): small wards ( $\leq 16$ beds), medium wards (17-27 beds) and large wards ( $\geq 28$ beds). The comparison was made between medians because the data are skewed and this was a better measure than the mean.

We conducted Quasi-Poisson regression analyses to assess the effect of ward closure (timing of closure) on outcome measures, controlling for time of year (winter or summer), ward size and ward type (elderly care wards). Outbreaks where the ward size was missing are omitted from the regression model (eg, 16\% of the outbreaks where no closure occurred). Quasi-Poisson regression provides more robust SDs than the standard Poisson regression methods where there is evidence of over dispersion in the model parameters. The model used was:

$$
\log _{\mathrm{e}}(\mathrm{Y})=\beta_{0}+\beta_{1} \mathrm{x}_{1}+\beta_{2} \mathrm{x}_{2}+\ldots+\beta_{\mathrm{n}} \mathrm{x}_{\mathrm{n}}
$$

where $\beta_{0}=$ intercept, $\beta_{1} x_{1}=$ closure group, $\beta_{2} x_{2}=$ ward size group, etc.

The estimated outcome measure can then be calculated as:

$$
\mathrm{Y}=\left(\mathrm{e}^{\beta_{0}}\right)\left(\mathrm{e}^{\beta_{1} \mathrm{x}_{1}}\right)\left(\mathrm{e}^{\beta_{2} \mathrm{x}_{2}}\right)\left(\mathrm{e}^{\beta_{\mathrm{n}} \mathrm{x}_{\mathrm{n}}}\right)
$$

Backwards stepwise regression was carried out starting with a full model including all variables and interaction terms between variables. Variables that were not significant $(p>0.1)$ were excluded from each of the models. We also tested for interactions between closure group and other factors. Interaction terms were excluded if the model was not significantly different from the model without the interaction term. The most parsimonious model including only variables that remained significant was used as the final model for each of the analyses. All analyses were carried out using R statistical software. ${ }^{11}$

\section{RESULTS}

Between January 2009 and December 2012, the HNORS received 5841 reported outbreaks of diarrhoea and vomiting. After exclusions (as outlined above) there were 3650 laboratory-confirmed norovirus outbreaks. Of these, 3437 (94\%) could be categorised into closure groups (as defined above). Seventy-eight per cent of outbreaks fell into the first category. Table 1 shows the ward characteristics by closure groups. The closure groups were similar with regard to each of the characteristics. There was a little difference between the ward

\begin{tabular}{|c|c|c|c|c|}
\hline \multirow[b]{2}{*}{ Ward characteristic } & \multicolumn{4}{|l|}{ Closure group } \\
\hline & $\begin{array}{l}\text { Prompt closure } \\
\text { N (\%) }\end{array}$ & $\begin{array}{l}\text { Closed in 4-6 days } \\
\mathrm{N}(\%)\end{array}$ & $\begin{array}{l}\text { Closed in } 7+\text { days } \\
\mathrm{N}(\%)\end{array}$ & $\begin{array}{l}\text { Not closed } \\
\text { N (\%) } \\
\end{array}$ \\
\hline \multicolumn{5}{|l|}{ Ward type } \\
\hline Elderly & $614(23)$ & $65(26)$ & $21(27)$ & $92(21)$ \\
\hline General med & $833(31)$ & 82 (33) & $18(23)$ & $154(35)$ \\
\hline Admissions/short stay & $241(9)$ & $11(4)$ & $3(4)$ & $31(7)$ \\
\hline Orthopaedic/trauma & $189(7)$ & $13(5)$ & $5(6)$ & $29(7)$ \\
\hline ITU & $7(<1)$ & $0(0)$ & $1(1)$ & $4(1)$ \\
\hline Respiratory/cardio & 355 (13) & $28(11)$ & $13(16)$ & $46(10)$ \\
\hline Gastroenterology & $80(3)$ & $11(4)$ & $4(5)$ & $9(2)$ \\
\hline Diabetes/nephrology & $120(5)$ & $9(4)$ & $1(1)$ & $21(5)$ \\
\hline Others & $231(9)$ & $29(12)$ & $13(16)$ & $54(12)$ \\
\hline Total & 2670 & 248 & 79 & 440 \\
\hline \multicolumn{5}{|l|}{ Ward size } \\
\hline$<17$ beds & $145(6)$ & $13(5)$ & $0(0)$ & $34(9)$ \\
\hline $17-27$ beds & $1001(40)$ & $116(48)$ & 37 (49) & $145(39)$ \\
\hline$\geq 28$ beds & $1380(55)$ & $112(46)$ & $38(51)$ & $191(52)$ \\
\hline Total & 2526 & 241 & 75 & 370 \\
\hline \multicolumn{5}{|l|}{ Year } \\
\hline 2009 & $419(16)$ & 33 (13) & $18(22)$ & 74 (17) \\
\hline 2010 & $860(32)$ & $89(36)$ & $19(24)$ & $140(32)$ \\
\hline 2011 & $538(20)$ & $61(25)$ & $16(20)$ & $104(24)$ \\
\hline 2012 & $853(32)$ & $65(26)$ & $26(33)$ & $122(28)$ \\
\hline Total & 2670 & 248 & 79 & 440 \\
\hline \multicolumn{5}{|l|}{ Summer/winter } \\
\hline Summer & $565(21)$ & $50(20)$ & $11(14)$ & 65 (14) \\
\hline Winter & 2105 (79) & $198(79)$ & $68(86)$ & $375(85)$ \\
\hline Total & 2670 & 248 & 79 & 440 \\
\hline
\end{tabular}

Table 1 Ward characteristics by closure group 
characteristics, size and type of ward and year of outbreak and season (winter/summer) for each of the closure groups.

\section{Closure versus non-closure}

Analysis of closed versus not closed suggested that wards were more likely to remain open in summer $\chi^{2}=7.52$ $\mathrm{p}=0.006$, and small wards were less likely to close compared with medium or large wards $\chi^{2}=6.67, p=0.01$. We did not find associations with other characteristics in this analysis.

\section{Closure group analysis}

The median duration of outbreak, duration of disruption and the number of patients affected were lower in outbreaks where there was a prompt closure compared with those outbreaks where it took longer period to close (table 2). However, the median duration of closure, staff affected and average cases per day of outbreak were higher in the prompt closure group (Kruskal-Wallace rank sum tests all $\mathrm{p}<0.001$ ). Lost bed-days was not significant.

\section{Regression analysis}

Table 3 shows the results of the regression analyses. The models suggest that (after controlling for season, ward size and type) the duration of outbreak and total disruption was shorter and fewer patients were affected in the prompt closure group (group 1) compared with closure groups 2 and 3. The duration of outbreaks where closure occurred seven or more days after the first onset date are almost twice as long as those where closure is prompt (see table 3 and also online supplementary figure S1 appendix). The duration of closure was shorter and there were fewer cases per day in the other closure groups compared with the prompt closure group.

Outbreaks where wards were not closed had fewer patients and staff affected and fewer cases per day of outbreak compared with prompt closure (the baseline group) but there was no statistical evidence for a difference in the duration of closure.
Outbreaks occurring on larger units, on care of the elderly wards, were significantly associated with longer outbreaks, longer disruption and more cases in most of the models. The number of bed-days lost was not significantly associated with the closure group, but there was a positive correlation with increasing ward size and a negative correlation with care of the elderly wards. We found no evidence of interaction between closure groups and other factors.

\section{DISCUSSION}

We approached this study from the perspective of assessing whether disruption caused by outbreaks of norovirus can be mitigated by closing wards early. We found that in $80 \%$ of outbreaks reported, closure occurred promptly. This, on reflection, should not have been surprising given that the guidelines produced in 2000 recommended ward closure (and in these guidelines it was a strong recommendation) as one of the measures to control an outbreak of diarrhoea and vomiting. ${ }^{12}$ However, these guidelines did not propose a time limit for closure. This was first recommended by Lopman $e t a l,{ }^{4}$ and at the time this study was carried out, it was not evident that the closure occurred rapidly, at least not in the area in which the study was conducted.

In our analysis, we have some evidence of a dose response, whereby, closing a bay or ward promptly (within 3 days of the first case occurring) in an outbreak of norovirus, the duration of the outbreak is shorter compared with the outbreaks where closure is not prompt. The duration of the outbreaks was longer in the closure group where closure was delayed to seven or more days. Furthermore, when closure did occur promptly, fewer patients were affected and the total duration of the disruption (first onset date to when the ward is reopened) is also shorter. It might be argued that the prompt closure during these outbreaks was beneficial. However, the interpretation of these results is not straightforward. Outbreaks where the ward was not closed at all also have similar characteristics in terms of the duration of outbreak and fewer people affected compared with the baseline prompt closure group. These

Table 2 Median (and IQR) number of people affected and days of disruption by closure groups

\begin{tabular}{|c|c|c|c|c|}
\hline \multirow[b]{2}{*}{ Outcome } & \multicolumn{4}{|l|}{ Closure group } \\
\hline & Prompt closure & Closed in 4-6 days & Closed in 7+ days & Not closed \\
\hline Duration of outbreak (days) & $7(4-9.75)$ & $9(7-12)$ & $14(10.75-18.25)$ & $6(4-11)$ \\
\hline Total duration of disruption (days) & $9(6-12)$ & $12(9-14)$ & $17(13-20)$ & NA \\
\hline Duration of closure (days) & $8(5-11)$ & $7(5-10)$ & $7(5-10)$ & NA \\
\hline Number of patients affected & $11(7-15)$ & $12(9-16)$ & $14.5(10-18)$ & $7(4-11.75)$ \\
\hline Number of staff affected & $2(0-5)$ & $3(1-6)$ & $2(1-5)$ & $1(0-3)$ \\
\hline Bed-days lost & $15(7-38)$ & $14(7-43)$ & $17(6-46.5)$ & NA \\
\hline Average cases per day & $2(1.3-2.9)$ & $1.6(1.2-2.2)$ & $1.2(0.8-1.8)$ & $1.3(0.8-2.0)$ \\
\hline Number of cases by time of closure & $2.4(1.5-3.8)$ & $7.0(5.3-10.0)$ & $11.0(8.3-15.0)$ & NA \\
\hline
\end{tabular}


Table 3 Regression model estimates for outcome by ward characteristic (figures in brackets are $95 \% \mathrm{Cls}$ )

\begin{tabular}{|c|c|c|c|c|c|c|c|c|}
\hline \multirow[b]{2}{*}{ Outcome } & \multirow[b]{2}{*}{$\begin{array}{l}\text { Baseline estimate } \\
\text { from modelt }\end{array}$} & \multicolumn{7}{|c|}{ Percentage increase/decrease over baseline by characteristic } \\
\hline & & $\begin{array}{l}\text { Closure group } 1 \\
\text { (not closed) }\end{array}$ & $\begin{array}{l}\text { Closure group } 2 \\
\text { (4-6 days) }\end{array}$ & $\begin{array}{l}\text { Closure group } 3 \\
(7+\text { days })\end{array}$ & $\begin{array}{l}\begin{array}{l}\text { Ward group } 2 \\
\text { (medium) }\end{array} \\
\end{array}$ & $\begin{array}{l}\text { Ward group } 3 \\
\text { (large) }\end{array}$ & $\begin{array}{l}\text { Elderly care } \\
\text { ward }\end{array}$ & Winter \\
\hline $\begin{array}{l}\text { Length of outbreak } \\
\text { (days) }\end{array}$ & $5.93(5.59 \text { to } 6.30)^{*}$ & 4 (1 to 7 ) & $32(27 \text { to } 38)^{*}$ & $99(87 \text { to } 101)^{*}$ & 11 (4 to 17$)$ & $22(15 \text { to } 29)^{\star}$ & $18(15 \text { to } 21)^{\star}$ & $7(4 \text { to } 10)^{\star \star}$ \\
\hline $\begin{array}{l}\text { Length of closure } \\
\text { (days) }\end{array}$ & $6.79(6.45 \text { to } 7.14)^{\star}$ & - & $-13(-9 \text { to }-17)^{\star}$ & $-12(-6$ to -19$)$ & $17(11 \text { to } 23)^{\star}$ & $28(21 \text { to } 35)^{\star}$ & $18(15 \text { to } 21)^{\star}$ & -- \\
\hline $\begin{array}{l}\text { Total length of } \\
\text { disruption (days) }\end{array}$ & $7.62(7.24 \text { to } 8.01)^{*}$ & 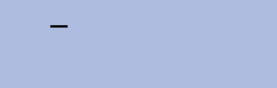 & $29(23 \text { to } 34)^{\star}$ & $82(69 \text { to } 95)^{\star}$ & $16(10 \text { to } 22)^{\star}$ & $23(16 \text { to } 29)^{*}$ & $18(15 \text { to } 21)^{\star}$ & -- \\
\hline $\begin{array}{l}\text { Patients affected } \\
\text { (number) }\end{array}$ & $6.19(5.89 \text { to } 6.52)^{\star}$ & $-24(-22 \text { to }-27)^{*}$ & $12(8 \text { to } 15)^{\star}$ & $24(17 \text { to } 30)^{\star}$ & $56(48 \text { to } 63)^{\star}$ & $86(76 \text { to } 95)^{\star}$ & $12(10 \text { to } 14)^{\star}$ & $10(7 \text { to } 12)^{*}$ \\
\hline $\begin{array}{l}\text { Staff affected } \\
\text { (number) }\end{array}$ & $2.01(1.88 \text { to } 2.35)^{\star}$ & $-47(-42 \text { to }-52)^{\star}$ & 12 (3 to 21$)$ & 16 (1 to 33 ) & $29(15 \text { to } 43)^{\star \star}$ & $24(11 \text { to } 37)^{\star \star}$ & -- & 29 (21 to 36$)$ \\
\hline $\begin{array}{l}\text { Lost bed-days } \\
\text { (days) }\end{array}$ & $13.44(11.54 \text { to } 15.65)^{\star}$ & - & 5 (1 to 15$)$ & 24 (6 to 44$)$ & $85(58 \text { to } 117)^{*}$ & $129(96 \text { to } 167)^{*}$ & $-17(-12 \text { to }-22)^{\star}$ & -- \\
\hline $\begin{array}{l}\text { Cases per day } \\
\text { (number) }\end{array}$ & $1.74(1.64 \text { to } 1.85)^{\star}$ & $-24(-21 \text { to }-28)^{*}$ & $-22(-12 \text { to }-26)^{*}$ & $-43(-37 \text { to }-49)^{\star}$ & $37(28 \text { to } 46)^{*}$ & $39(31 \text { to } 64)^{*}$ & $-8(-5 \text { to }-11)^{\star \star}$ & -- \\
\hline $\begin{array}{l}\text { Cases by close } \\
\text { (number) }\end{array}$ & $2.15(2.00 \text { to } 2.32)^{*}$ & - & $176(165 \text { to } 186)^{\star}$ & $302(282 \text { to } 322)^{\star}$ & $42(31 \text { to } 53)^{\star}$ & $40(30 \text { to } 51)^{\star}$ & -- & -- \\
\hline
\end{tabular}


findings might suggest that there is no compelling evidence that closing the ward is an effective way of curtailing an outbreak of norovirus.

There are limitations to this study. The analysis was carried out on summary data collected on outbreaks from a national web-based reporting scheme. During data entry, there are some built-in data validation steps, but despite this it is difficult to validate all of the data entered and we have to accept that there might be some errors. For example, where there was no information on closures (where the reporter has not selected YES at the question on whether the outbreak led to closure), we have assumed that the ward did not close. It is conceivable that in some of these outbreaks closures did occur. In this case, the outcomes in this category (not closed) might have been more favourable to this group, especially if the ward closed promptly.

It is also difficult to unpick some of the questions around the ward characteristics that make for differences in the outcomes. For example, outbreaks where wards were promptly closed might have been shorter because they were in smaller wards and therefore were shorter simply because the pool of susceptible patients was small. We also assumed that all other aspects of infection control, including increased hygiene measures, are carried out during outbreaks and that these procedures do not differ between outbreaks.

The current guidelines suggest that wards are reopened following terminal cleaning, which is normally after $72 \mathrm{~h}$ after the onset of the last known case. However, we have to accept that, in some circumstances, this might have to be altered in order to respond to situations, for example, if there have been a number of ward closures and there is pressure for hospitals to reopen to provide services. We have excluded from the analysis outbreaks on some wards which cannot close (eg, intensive care units) for operational reasons, so these will not have skewed the results. Furthermore, each outbreak was limited only to one ward, because we ask for outbreaks on each ward to report separately, and this might not have been the case for every outbreak. Although we were able to exclude outbreaks where it was clear from the report that the outbreak involved more than one ward, it is possible that some outbreaks spread from one ward to another. In this case, our estimate of the duration of the outbreak might be shorter than the actual event. The current approaches to collect samples during outbreaks of norovirus, where several samples are collected from the beginning of the outbreak and subsequent cases are not always sampled, militate against answering the question about spread between wards. Methods have been developed which can determine these transmission events ${ }^{13}{ }^{14}$ and it is now possible to show if the virus has been passed from one person to another or if patients have contracted the virus from separate introductions. In order to understand the transmission events and the way in which the virus can spread throughout a hospital, a dedicated study would be needed where samples are taken from patients who fall ill on each ward, along with more detailed data on onset times and position on the ward when the person became ill.

The analysis of number of cases per day (although limited because it is essentially an average) suggests that some outbreaks were 'slow burning' in which there are a just a few new cases occurring each day of the outbreak. This might explain the differences in the data, whereby the longer it takes to close a ward the longer the outbreak lasts and more patients are affected overall. In all outbreaks where closure occurred, the duration of closure is similar, suggesting that the act of closing is beneficial contributing to curtailing the outbreak. The number of cases occurring during an outbreak might not follow an even progression, sometimes several cases can come to light on 1 day and 1 or 2 days elapse between the next cases. However, it is not possible to tell this from summary data; again one would need more data on individual onset dates and the number of new cases on each day of the outbreak and this would require an observational study. Norovirus has a short incubation period and the estimated serial interval is short (possibly around 2 days) ${ }^{15}$ so it would not be unreasonable to expect many cases to occur in the first few days of an outbreak.

For our analysis, we had a dataset considerably larger than that used in the study by Lopman et al. A major difference with our data is the finding that, in the majority of outbreaks, wards were closed within 3 days. In the study by Lopman et al, the wards that were in the prompt closure group accounted for only $14 \%$ of the outbreaks analysed. Moreover, the non-prompt closure group was comprised of outbreaks where wards were not closed and those that closed later than 3 days.

We also restricted our analysis to outbreaks that were laboratory confirmed as due to norovirus; therefore, it is unlikely that these outbreaks would have atypical characteristics to those not associated with norovirus infections. What is evident from our analysis is that ward size and elderly care wards had an independent effect on the length of outbreaks. Lopman et al found that the number of beds on a ward and elderly care wards was related to an increased hazard of outbreaks occurring. ${ }^{2}$

Our analyses have implications for the control of norovirus in hospitals and other closed settings such as care homes. The finding that larger ward size is associated with increased duration of outbreaks fits in with other studies which suggested that enclosing bays and putting doors on bays were beneficial and shortened the duration of outbreaks. ${ }^{78}$

In the USA, outbreaks in hospitals are rarely reported and hospitals tend to have single or double occupied rooms rather than large wards. The notable feature in a large hospital outbreak reported in the USA was the high ratio of staff to patients affected and the higher attack rates in staff compared with patients. ${ }^{3}$ Patients are more likely to spread norovirus infections during 
outbreaks in enclosed settings rather than healthcare workers ${ }^{16}$ and there is good evidence that proximity of patients to one another ${ }^{15}$ and vomiting are the likely principle driver of outbreaks. ${ }^{17} 18$ Furthermore, the time it takes for an infected person to infect another shortens as an epidemic unfolds. ${ }^{19}$ In a ward with many beds, it is easy to see how this could cause an outbreak to infect a large number of patients. If bays were enclosed with solid physical barriers such as doors and floor to ceiling walls, this effectively creates small rooms in which onward transmission can be more easily prevented.

Is it still reasonable to suggest that closing a ward or bay is an effective tool in curtailing an outbreak of norovirus? It has been previously shown that it is difficult to evaluate the effectiveness of individual infection control methods. ${ }^{6}$ It is likely that they are effective only when introduced together (in today's parlance as a bundle). One aspect of infection control is closing an affected area and reducing the risk of further exposure to other patients. Taking the decision to close an area is a tacit indicator to staff working in the area and serves to heighten the awareness of a problem and the need to implement infection control procedures. Leaving a ward open while patients are symptomatic increases the risk of exposing newly admitted patients. If these newly exposed patients are subsequently moved to another part of the hospital, they are likely to contribute to onward transmission. The duration of closure was similar in all of the closure groups, suggesting this is an effective strategy particularly in larger wards, and during winter when outbreaks are more common.

What this analysis of the HNORS data provides is a baseline to judge how outbreaks of norovirus might unfold should hospitals begin to change their infection control strategy away from whole-ward closures as the new guidelines suggest. One of the strengths of surveillance data is its sustainability which allows for continuous collection of consistent data relatively cheap. Continued monitoring of the HNORS data in the future, in light of the recent changes to the guidance, would show if the burden of norovirus outbreaks changes, particularly in terms of increased duration and patients affected.

\section{Conclusion}

A prompt action is required in order to help control outbreaks of norovirus. However, more detailed studies can help to unravel the complexities around ward characteristics and help to explain why some outbreaks tend to come to an end without further action. This would entail collection of information on ward type, number of cases on each day of the outbreak, position in the ward when the patient became ill, whether the patient had been moved in the 24-48 $\mathrm{h}$ prior to symptoms and how many patients had become symptomatic before the closure.
Acknowledgements The authors would like to thank Dr Ben Lopman (CDC Atlanta) for his constructive comments in preparing this manuscript; they would also like to thank the infection control staff at the National Hearth Service (NHS) hospitals for taking the time to input the data into the reporting scheme.

Contributors All authors contributed to the design of the study and writing of the paper. JPH conducted the analysis and led the writing of the paper.

Funding This research received no specific grant from any funding agency in the public, commercial or not-for-profit sectors.

Competing interests None.

Provenance and peer review Not commissioned; externally peer reviewed.

Data sharing statement The data are from a database of outbreaks collected centrally. The data are regularly used for updating information on the current situation of norovirus activity on the PHE website.

Open Access This is an Open Access article distributed in accordance with the Creative Commons Attribution Non Commercial (CC BY-NC 3.0) license, which permits others to distribute, remix, adapt, build upon this work noncommercially, and license their derivative works on different terms, provided the original work is properly cited and the use is non-commercial. See: http:// creativecommons.org/licenses/by-nc/3.0/

\section{REFERENCES}

1. Elliot AJ, Cross KW, Fleming DM. Acute respiratory infections and winter pressures on hospital admissions in England and Wales 1990-2005. J Public Health (Oxf) 2008;30:91-8.

2. Lopman BA, Andrews N, Sarangi J, et al. Institutional risk factors for outbreaks of nosocomial gastroenteritis: survival analysis of a cohort of hospital units in South-west England, 2002-2003. J Hosp Infect 2005;60:135-43.

3. Johnston CP, Qu H, Ticehurst JR, et al. Outbreak management and implications of a nosocomial norovirus outbreak. Clin Infect Dis 2007;45:534-40.

4. Lopman BA, Reacher MH, Vipond IB, et al. Epidemiology and cost of nosocomial gastroenteritis, Avon, England, 2002-2003. Emerg Infect Dis 2004;10:1827-34.

5. Danial J, Cepeda JA, Cameron F, et al. Epidemiology and costs associated with norovirus outbreaks in NHS Lothian, Scotland 20072009. J Hosp Infect 2011;79:354-8.

6. Harris JP, Lopman BA, O'Brien SJ. Infection control measures for norovirus: a systematic review of outbreaks in semi-enclosed settings. J Hosp Infect 2010;74:1-9.

7. Haill CF, Newell P, Ford C, et al. Compartmentalization of wards to cohort symptomatic patients at the beginning and end of norovirus outbreaks. J Hosp Infect 2012;82:30-5.

8. Illingworth E, Taborn E, Fielding D, et al. Is closure of entire wards necessary to control norovirus outbreaks in hospital? Comparing the effectiveness of two infection control strategies. J Hosp Infect 2011;79:32-7.

9. Guidelines for the management of norovirus outbreaks in acute and community health and social care settings. 2012. http://www.hpa org.uk/webc/HPAwebFile/HPAweb_C/1317131639453

10. MacCannell T, Umscheid CA, Agarwal RK, et al. Guideline for the prevention and control of norovirus gastroenteritis outbreaks in healthcare settings. Infect Control Hosp Epidemiol 2011;32:939-69.

11. R Development Core Team (2009). R: a language and environment for statistical computing. R Foundation for Statistical Computing, 2012.

12. Chadwick PR, Beards G, Brown D, et al. Management of hospital outbreaks of gastro-enteritis due to small roundstructured viruses. $J$ Hosp Infect 2000;45:1-10.

13. Xerry J, Gallimore Cl, Iturriza-Gomara M, et al. Transmission events within outbreaks of gastroenteritis determined through analysis of nucleotide sequences of the P2 domain of genogroup II noroviruses. $J$ Clin Microbiol 2008;46:947-53.

14. Xerry J, Gallimore Cl, Iturriza-Gomara M, et al. Tracking the transmission routes of genogroup II noroviruses in suspected food-borne or environmental outbreaks of gastroenteritis through sequence analysis of the P2 domain. J Med Virol 2009;81:1298-304.

15. Harris JP, Lopman BA, Cooper BS, et al. Does spatial proximity drive norovirus transmission during outbreaks in hospitals? BMJ Open 2013;3:e003060. 
16. Heijne JC, Rondy M, Verhoef L, et al. Quantifying transmission of norovirus during an outbreak. Epidemiology 2012;23:277-84.

17. Caul EO. Hyperemesis hiemis-a sick hazard. J Hosp Infect 1995;30(Suppl):498-502.
18. Thornley CN, Emslie NA, Sprott TW, et al. Recurring norovirus transmission on an airplane. Clin Infect Dis 2011;53:515-20.

19. Kenah E, Lipsitch M, Robins JM. Generation interval contraction and epidemic data analysis. Math Biosci 2008;213:71-9. 